\title{
Discordance Between Drug Adherence as Reported by Patients and Drug Importance as Assessed by Physicians
}

\author{
Stéphanie Sidorkiewicz, $M D^{1,2}$ \\ Viet-Thi Tran, $M D, P b D^{2,3}$ \\ Cécile Cousyn, $M D^{3}$ \\ Elodie Perrodeau, $M \mathrm{Sc}^{2}$ \\ Pbilippe Ravaud, $M D, P b D^{2,4,5}$ \\ 'Department of General Medicine, Paris \\ Descartes University, Paris, France \\ ${ }^{2}$ METHODS Team, INSERM U1153, Epi- \\ demiology and Statistics Sorbonne Paris \\ Cité Research Centre, France \\ ${ }^{3}$ Department of General Medicine, Paris \\ Diderot University, Paris, France \\ ${ }^{4}$ French Cochrane Centre, Paris, France \\ ${ }^{5}$ Department of Epidemiology, Mailman \\ School of Public Health, Columbia Univer- \\ sity, New York City, New York
}

Conflicts of interest: authors report none.

\section{CORRESPONDING AUTHOR}

Viet-Thi Tran, MD, PhD Hôpital Hôtel Dieu, Centre d'Épidémiologie Clinique 1 place du Parvis Notre-Dame Paris 75181, France thi.tran-viet@htd.aphp.fr

\begin{abstract}
PURPOSE Among patients on long-term medical therapy, we compared (1) patient and physician assessments of drug adherence and of drug importance and (2) drug adherence reported by patients with drug importance as assessed by their physicians.
\end{abstract}

METHODS We recruited to the study patients receiving at least 1 long-term drug treatment from both hospital and ambulatory settings in France. We compared drug adherence reported by patients and drug importance assessed by physicians using Spearman correlation coefficients. Reasons for nonadherence were collected with open-ended questions and classified as intentional or unintentional.

RESULTS Between April and August 2014, we recruited 128 patients taking 498 drugs. Patients and physicians showed only weak agreement in their assessments of drug adherence $(r=-0.25 ; 95 \% \mathrm{Cl},-0.37$ to -0.11$)$ and drug importance $(r=0.07 ; 95 \% \mathrm{Cl}, 0.00$ to 0.13$)$. We did not find any correlation between physician-assessed drug importance and patient-reported drug adherence ( $r=-0.04 ; 95 \% \mathrm{Cl}_{1}-0.14$ to 0.06$)$. In all, 94 (18.9\%) of the drugs that physicians considered important were not correctly taken by patients. Patients intentionally did not adhere to $26(48.1 \%)$ of the drugs for which they reported reasons for nonadherence.

CONCLUSIONS We found substantial discordance between patient and physician evaluations of drug adherence and drug importance. Nearly $20 \%$ of drugs considered important by physicians were not correctly taken by patients. These findings highlight the need for better patient-physician collaboration in drug treatment.

Ann Fam Med 2016;14:415-421. doi: 10.1370/afm.1965.

\section{INTRODUCTION}

$\mathrm{N}$ onadherence, defined as the extent to which a person's behavior fails to coincide with medical advice, may lead to negative outcomes and long-term mortality, ${ }^{1,2}$ especially among patients with chronic conditions and on complex medication regimens. ${ }^{3,4}$ Approximately $50 \%$ of patients stop taking their medications 6 months after drug initiation. ${ }^{3,5}$ Reasons for nonadherence go beyond simple forgetfulness. Patients' perceptions and beliefs are crucial in their medication-taking behaviors. ${ }^{6}$

Two types of drug nonadherence are usually distinguished: intentional and unintentional., ${ }^{4,7}$ Intentional nonadherence is an active decision by patients who decide not to take medications as prescribed because of beliefs, ${ }^{8}$ perceived need or benefit, ${ }^{9}$ side effects, or burden of treatment. Unintentional nonadherence is a passive process whereby patients fail to adhere to treatments because of circumstances beyond their control. ${ }^{7}$ Individual adherence to the different drugs a patient takes can therefore vary considerably, ${ }_{1}^{10,11}$ with various consequences depending on the drug or disease of interest. ${ }^{12}$

Not all drugs patients take have the same impact on their health outcomes: some are intended to prevent complications, others to reduce symptoms. Physicians and patients may differentially balance the need for each drug, which can result in a discordance in their priorities. ${ }^{13,14}$ 
In this study, we aimed to investigate whether patients adhere to drugs considered important by their physicians. For patients on long-term drug treatment, we compared drug adherence as reported by patients with drug importance as assessed by their usual primary care physician.

\section{METHODS}

\section{Setting and Participants}

We recruited consecutive patients from 6 general practices and 6 care units of university hospitals in France. Patients were aged 18 years or older and were receiving at least 1 long-term drug treatment, defined as initiation of a drug that was to be taken for at least 30 days and that was not prescribed solely for as-needed use or for an acute condition. We excluded patients with cognitive impairment or a language barrier, and those receiving medication from a nurse or a home care provider. All patients provided written consent to participate in the study. The study protocol was approved by the institutional review board of University Paris Descartes (IRB 0001072).

\section{Data Collection}

For each patient, 2 investigators (C.C. and S.S.) identified drugs prescribed for long-term use by reviewing medical records and by asking patients if they used additional over-the-counter medications. The 2 investigators independently assigned each drug to a therapeutic class by using a system adapted from pharmacy claims. ${ }^{15}$

\section{Patient Assessments}

Patients were asked to assess 3 aspects of each drug taken. First, adherence to the drug was assessed by use of a validated self-report adherence instrument that we developed in a previous study. ${ }^{16}$ This 5 -item tool illustrates items by practical examples and pictographs to assess drug adherence and provide information about behaviors during drug intake. The results generate adherence levels ranging from 1 (high drug adherence) to 6 (drug discontinuation). Each level corresponds to given medicine-taking behaviors. For example, level 4 (poor adherence) corresponds to "drug holidays for 2-3 days" and/or "missing doses $\geq 1$ /week."

Second, patient-perceived importance of the given drug was assessed by using the first item of the Adherence Estimator, ${ }^{17}$ an instrument that predicts nonadherence associated with beliefs about medicine. The first item, "I am convinced of the importance of my prescription medication," assesses the perceived need for medication on a 6-step scale ranging from "agree completely" to "disagree completely."
Third, patients were asked an open-ended question about the reason for drug nonadherence. Specifically, we asked, "If you happen to skip doses, why? (eg, omission, drug side effect, too much medication to take)." We evaluated the clarity of the question during cognitive testing in a previous study ${ }^{16}$ by a double interview method. Discrepancies between what was intended and what was understood by patients were noted to adapt the wording.

\section{Physician Assessments}

For each recruited patient, we contacted his or her primary care physician by mail, with a reminder after 1 month. For each drug taken, we asked physicians to assess 2 aspects. First, we asked them to assess the patient's adherence to the drug by making their best estimate of adherence on an 11-step rating scale ranging from 0 (very poor) to 10 (excellent). This scale was inspired by the instrument of Lu et $\mathrm{al}^{18}$ and by a question used in a study conducted among physicians. ${ }^{19}$ Our version for evaluation by physicians showed acceptable content validity during cognitive testing in a previous study. ${ }^{16}$

Second, we asked physicians to rate the importance of the drug by giving their best estimate of the drug's importance for patient health by using an 11-step rating scale ranging from 0 (not important) to 10 (very important). This scale was not validated. We used a question similar to the one for drug adherence to reduce the questionnaire burden for physicians.

\section{Analysis}

Data are reported as numbers (percentages) for categorical variables and means (SDs) or medians (interquartile range $[\mathrm{IQR}]$ ) for quantitative variables. We analyzed outpatients and inpatients separately to determine any substantial differences between the 2 groups. Complete Case Analysis was performed to manage missing data. Statistical analyses were performed in part with R version 3.2.2 (http://www.r-project.org; R Foundation).

Given that we compared ratings using 2 different ordinal scales, we calculated Spearman correlation coefficients $(r)$ for comparison of physician and patient assessments of drug importance and of drug adherence. We considered correlation to be moderate when $r$ fell in the range of 0.5 to 0.7 and low when $r$ fell in the range of 0.3 to $0.5 . .^{20,21}$ The $95 \%$ confidence intervals $(\mathrm{CIs})$ were determined by a bootstrap method to account for the clustered structure of our data (several drugs taken by a same patient, and possibly several patients evaluated by the same physician). Statistical tests were 2 -sided, and we considered $P<.05$ to be statistically significant. 
We calculated the Spearman correlation coefficients $(r)$ as described above for correlation analysis of the drug importance assessed by physicians and drug adherence reported by patients. To put this analysis into a more clinical perspective, we dichotomized the 2 variables by using the median of the scales: physicians' rating of the importance of drugs was dichotomized into categories of less important (rating $\leq 5$ ) and important (rating $\geq 6$ ), and patient-reported adherence was dichotomized into categories of good (rating of $\leq 3$, corresponding to adherence better than 2 omissions per month) or poor (rating of $\geq 4$, corresponding to drug holidays or more than 1 drug omission per week). We thereby defined 3 situations: (1) patients reported good adherence to drugs rated important by physicians (a situation that health care professionals try to achieve), (2) patients reported poor adherence to drugs rated important by physicians (potential problematic nonadherence), and (3) physicians rated drugs as less important whatever the patient's adherence (potential overtreatment).

\section{Reasons for Nonadherence}

Two investigators (S.S., C.C.) independently classified qualitative answers to the open-ended question about reasons for nonadherence as intentional or unintentional by using a framework developed by Gadkari and McHorney. ${ }^{7}$ Unintentional reasons were forgetting to take medication, running out of medication, and careless at times about taking medications; all other reasons were classified as intentional. We focused on studying reasons for nonadherence among patients who reported poor adherence to drugs that were rated important by physicians (potential problematic nonadherence).

\section{RESULTS}

\section{Participants}

From May to August 2014, we obtained patients' assessments of drug adherence and their primary care physicians' assessments of drug importance for 498 drugs taken by 128 patients. The physician response rate was $33.5 \%$. The patients had a median age of 59.8 years (IQR, 42.5-72.4 years); $71.1 \%$ were women and $70.3 \%$ were outpatients (Table 1 ). The physicians had a median age of 57.4 years (IQR, $49.8-62.4$ years) $; 41.0 \%$ were men and $94.9 \%$ were general practitioners (Supplemental Appendix, Table 1, http://www.annfammed. org/content/14/5/415/suppl/DC1). Findings for outpatients and inpatients separately were largely the same, so we present the results for the entire cohort; results for each sample individually are given in the Supplemental Appendix, Table 2, http://www.annfammed.org/ content/14/5/415/suppl/DC1.
Table 1. Patient Characteristics ( $\mathrm{N}=128$ )

\begin{tabular}{lc}
\hline Characteristic & Value \\
\hline Age, median (IQR), y & $59.8(42.5-72.4)$ \\
Sex, male, No. (\%) & $37(28.9)$ \\
Marital status & \\
Married or in civil union, No. (\%) & $49(37.8)$ \\
Live-in partner, No. (\%) & $9(7.1)$ \\
Single, No. (\%) & $35(27.6)$ \\
Separated, No. (\%) & $20(15.7)$ \\
Widowed, No. (\%) & $15(11.8)$ \\
Highest education level & \\
Primary school, No. (\%) & $31(25.2)$ \\
Secondary school, No. (\%) & $48(39.0)$ \\
College, No. (\%) & $45(35.8)$ \\
Place of recruitment & \\
Inpatient setting, No. (\%) & $38(29.7)$ \\
Outpatient setting, No. (\%) & $90(70.3)$ \\
Medications per patient, median (IQR), No. & $3.0(2.0-6.0)$ \\
\hline IQR = interquartile range. & \\
\hline
\end{tabular}

\section{Correlation of Patient and Physician Assessments of Drug Importance and Drug Adherence}

We obtained both patient and physician assessments of drug importance for 487 drugs. Results are detailed in Table 2 and plotted in the Supplemental Appendix, Figure 1, http://www.annfammed.org/content/14/5/415/ suppl/DC1. The correlation between patient and physician assessments of drug importance was weak $(r=0.07 ; 95 \% \mathrm{CI}, 0.00-0.13)$.

We obtained both patient and physician assessments of drug adherence for 488 drugs. The correlation between these assessments was likewise weak $(r=-0.25 ; 95 \% \mathrm{CI},-0.37$ to -0.11$)$. Results are detailed in the Supplemental Appendix, Figure 2, http://www. annfammed.org/content/14/5/415/supp1/DC1.

\section{Correlation Between Patient-Reported Drug Adherence and Physician-Assessed Drug Importance}

We evaluated patient-reported drug adherence and physician-assessed drug importance for 498 drugs. Results are detailed in Table 3 and plotted in the Supplemental Appendix, Figure 3, http://www.annfammed.org/ content/14/5/415/suppl/DC1. The 2 assessments were not correlated $(r=-0.04 ; 95 \% \mathrm{CI},-0.14$ to 0.06$)$. For 339 drugs $(68.1 \%)$, patients reported good adherence to drugs evaluated as important by their physicians. But for 94 drugs (18.9\%), patients reported poor adherence even though their physicians evaluated them as important (a situation of potential problematic nonadherence). This poor adherence concerned mainly heart drugs, namely, antihypertensive medications, platelet aggre- 
Table 2. Importance of 487 Drugs According to Patients and Physicians

\begin{tabular}{|c|c|c|c|c|c|c|}
\hline \multirow[b]{2}{*}{$\begin{array}{l}\text { Physician Rating } \\
\text { of Importance }\end{array}$} & \multicolumn{6}{|c|}{ Patient Rating of Importance ${ }^{b}$} \\
\hline & $\begin{array}{c}6 \\
\text { (352 Drugs) }\end{array}$ & $\begin{array}{c}5 \\
\text { (76 Drugs) }\end{array}$ & $\begin{array}{c}4 \\
\text { (36 Drugs) }\end{array}$ & $\begin{array}{c}3 \\
\text { (16 Drugs) }\end{array}$ & $\begin{array}{c}2 \\
\text { (1 Drug) }\end{array}$ & $\begin{array}{c}1 \\
\text { (6 Drugs) }\end{array}$ \\
\hline 0 (10 drugs) & $8(1.6)$ & $0(0.0)$ & $1(0.2)$ & $0(0.0)$ & $1(0.2)$ & $0(0.0)$ \\
\hline 1 (3 drugs) & $2(0.4)$ & $1(0.2)$ & $0(0.0)$ & $0(0.0)$ & $0(0.0)$ & $0(0.0)$ \\
\hline 2 (3 drugs) & $2(0.4)$ & $1(0.2)$ & $0(0.0)$ & $0(0.0)$ & $0(0.0)$ & $0(0.0)$ \\
\hline 3 (11 drugs) & $7(1.4)$ & $1(0.2)$ & $1(0.2)$ & $1(0.2)$ & $0(0.0)$ & $1(0.2)$ \\
\hline 4 (11 drugs) & $11(2.3)$ & $0(0.0)$ & $0(0.0)$ & $0(0.0)$ & $0(0.0)$ & $0(0.0)$ \\
\hline 5 (29 drugs) & $15(3.1)$ & $8(1.6)$ & $4(0.8)$ & $2(0.4)$ & $0(0.0)$ & $0(0.0)$ \\
\hline 6 (48 drugs) & $35(7.2)$ & $9(1.8)$ & $4(0.8)$ & $0(0.0)$ & $0(0.0)$ & $0(0.0)$ \\
\hline 7 (47 drugs) & $29(6.0)$ & $8(1.6)$ & $5(1.0)$ & $4(0.8)$ & $0(0.0)$ & $1(0.2)$ \\
\hline 8 (98 drugs) & $66(13.6)$ & $19(3.9)$ & $10(2.0)$ & $1(0.2)$ & $0(0.0)$ & $2(0.4)$ \\
\hline 9 (59 drugs) & 48 (9.9) & $5(1.0)$ & $3(0.6)$ & $2(0.4)$ & $0(0.0)$ & $1(0.2)$ \\
\hline 10 (168 drugs) & $129(26.5)$ & $24(4.9)$ & $8(1.6)$ & $6(1.2)$ & $0(0.0)$ & $1(1.0)$ \\
\hline
\end{tabular}

gation inhibitors, and other cardiac agents (17 drugs, $18.1 \%)$; oral blood glucose-lowering drugs and insulin (13 drugs, 13.8\%); and drugs for airway diseases (12 drugs, 12.8\%). For 65 drugs (13.0\%), physicians rated drugs as less important whatever the patient's adherence (a situation of potential overtreatment). These agents were mainly drugs for psychiatric diseases, that is, antidepressants and anxiolytics (8 drugs, $12.3 \%)$; drugs for treating bone diseases such as osteoporosis ( 7 drugs, $10.8 \%)_{i}$ and drugs for treating symptoms such as functional gastrointestinal disorders or phlebotonic agents for venous insufficiency (6 drugs, 9.2\%).

\section{Reasons for Nonadherence}

Patients gave reasons for nonadherence for 115 drugs. For 73 of these drugs $(63.5 \%)$, the reasons were classified as unintentional, meaning the patient forgot to take the drug, ran out of medication, or was careless at times about taking $\mathrm{it}_{i}$ for 37 (32.2\%), the reases were classified as intentional, meaning the patient voluntarily decided not to take the drug; and for 5 (4.3\%), both. Reasons are detailed in the Supplemental Appendix, Table 3, http:// www.annfammed.org/content/14/5/415/suppl/DC1.

Among the 94 drugs that physicians evaluated as important but to which patients did not correctly adhere, we collected reasons for nonadherence for $54(57.4 \%)$. For about one-half of these drugs (26, or $48.1 \%)$, patients did not take them for intentional reasons.

\section{DISCUSSION}

We evaluated self-reported drug adherence by patients and drug importance as assessed by their physician for 498 drugs. A total of 94 drugs (18.9\%) that physicians considered important were not correctly taken by patients, which may lead to potential harmful consequences. Patients did not take about one-half of these drugs for intentional reasons, which confirm results from other studies. ${ }^{3,22}$ This discordance between patient adherence and physicians' assessment of drug importance may be due to a lack of patient-centered communication, therefore, it may be possible to reduce it by encouraging discussion between patients and physicians about medications, especially for patients having the poorest understanding of their medications $^{23}$ and fewer beliefs in the need for medications. ${ }^{24}$ Indeed, when patients intentionally do not adhere to a treatment regimen, they may view their behavior as rational, whereas the physician considers it an irrational decision. ${ }^{6}$ For example, patients may focus on medications for relief of immediate symptoms, whereas physicians may tend to focus on medications to prevent currently asymptomatic chronic conditions.

Physicians rated 65 drugs (13.0\%) as less important for patient health, although these drugs were prescribed. This situation raises questions about overtreatment and drug appropriateness. The benefit-to-harm ratio of drugs combined with patient goals may help determine treatment priorities ${ }^{25}$ to avoid excessive polypharmacy and reduce the burden of treatment. ${ }^{26}$

\section{Clinical Implications}

This study raises the need to reconcile patient and physician perceptions on drug therapy. A first way to reconcile viewpoints could be to encourage better patient-physician collaboration in drug treatment. In the current context of managing multimorbidity 
Table 3. Patient-Reported Adherence to 498 Drugs and Drug Importance According to Their Physician

\begin{tabular}{|c|c|c|c|c|c|c|}
\hline \multirow[b]{2}{*}{$\begin{array}{l}\text { Physician Rating } \\
\text { of Importance }\end{array}$} & \multicolumn{6}{|c|}{ Patient-Reported Adherence } \\
\hline & $\begin{array}{c}\text { High } \\
\text { (265 Drugs) }\end{array}$ & $\begin{array}{c}\text { Good } \\
\text { (46 Drugs) }\end{array}$ & $\begin{array}{l}\text { Moderate } \\
\text { (77 Drugs) }\end{array}$ & $\begin{array}{c}\text { Poor } \\
\text { (50 Drugs) }\end{array}$ & $\begin{array}{l}\text { Very Poor } \\
\text { (39 Drugs) }\end{array}$ & $\begin{array}{c}\text { Discontinuation } \\
\text { (21 Drugs) }\end{array}$ \\
\hline 0 (9 drugs) & $6(1.2)$ & $0(0.0)$ & $1(0.2)$ & $1(0.2)$ & $1(0.2)$ & $0(0.0)$ \\
\hline 1 (3 drugs) & $2(0.4)$ & $1(0.2)$ & $0(0.0)$ & $0(0.0)$ & $0(0.0)$ & $0(0.0)$ \\
\hline 2 (3 drugs) & $1(0.2)$ & $0(0.0)$ & $0(0.0)$ & $0(0.0)$ & $1(0.2)$ & $1(0.2)$ \\
\hline 3 (10 drugs) & $3(0.6)$ & $0(0.0)$ & $2(0.4)$ & $1(0.2)$ & $0(0.0)$ & $4(0.8)$ \\
\hline 4 (12 drugs) & $7(1.4)$ & $0(0.0)$ & $2(0.4)$ & $1(0.2)$ & $2(0.4)$ & $0(0.0)$ \\
\hline 5 (28 drugs) & $19(3.8)$ & $1(0.2)$ & $4(0.8)$ & $3(0.6)$ & $1(0.2)$ & $0(0.0)$ \\
\hline 6 (49 drugs) & $22(4.4)$ & $7(1.4)$ & $10(2.0)$ & $5(1.0)$ & $3(0.6)$ & $2(0.4)$ \\
\hline 7 (48 drugs) & $29(5.8)$ & $3(0.6)$ & $3(0.6)$ & $4(0.8)$ & $6(1.2)$ & $3(0.6)$ \\
\hline 8 (98 drug) & $48(9.6)$ & $11(2.2)$ & $15(3.0)$ & $13(2.6)$ & $7(1.4)$ & $4(0.8)$ \\
\hline 9 (63 drug) & $33(6.6)$ & $7(1.4)$ & $7(1.4)$ & $10(2.0)$ & $4(0.8)$ & $2(0.4)$ \\
\hline 10 (175 drugs) & 95 (19.1) & $16(3.2)$ & $33(6.6)$ & $12(2.4)$ & $14(2.8)$ & $5(1.0)$ \\
\hline
\end{tabular}

in primary care, ${ }^{27,28}$ patient-centered care with shared decision making seems to be a key to managing patient complexity ${ }^{25,28,29}$ and to achieving minimally disruptive medicine. ${ }^{30}$ Physicians have to reach an optimal patientphysician relationship, which requires good communication and may result in better health outcomes, ${ }^{31}$ especially for medication adherence. ${ }^{32}$ Studies suggest that the primary goal of collaboration is to reduce asymmetry in information to accomplish mutual decision making. Physicians can indeed be considered the experts in medicine and patients the experts in their own lives. ${ }^{33}$ Assessing drug adherence in primary care settings in a nonthreatening way ${ }^{3}$ and recognizing the challenges of taking medications regularly ${ }^{34}$ may help facilitate patient-physician discussion about medications ${ }^{35,36}$ and about patient knowledge and beliefs. ${ }^{33}$

Another way to bridge the gap between patients and physicians could be to encourage collaboration between all health professionals involved in ambulatory care. ${ }^{37}$ Pharmacist counseling has been shown to be effective to improve patient adherence and health outcomes. ${ }^{38}$ The role of pharmacists ranges from dispensing medication to counseling patients. Using their drug expertise, they may also be useful to physicians by ensuring that drugs do not interact in a harmful way, by monitoring adverse effects, or by advising physicians on drug decisions. Nurses or physician assistants could also be an important part of this patient care team by answering patient questions and emphasizing the importance of the prescribed treatment at each step of the care process. ${ }^{39}$

Our study showed that some drugs correctly taken by patients were not considered to be important by physicians. This phenomenon may lead to polypharmacy and a higher burden of treatment. ${ }^{26}$ Nonadher- ence may be a suitable trigger for deprescribing ${ }^{40}$ by reducing the number of unnecessary or inappropriate medications, and reinforcing adherence to other drugs.

Our findings highlight the importance of regularly assessing adherence, medication by medication, for patients who are on drugs long term. If patients show poor adherence, physicians should reconsider the risk-benefit balance of the drugs. Some drugs have low value and may be responsible for harmful interactions or adverse effects. In certain cases, an unfavorable risk-benefit balance of the drug combined with patient nonadherence may lead physicians to consider deprescription.

\section{Limitations}

Our study has several limitations. First, the patients were not wholly representative of those on long-term drug therapy, as they were recruited in a small number of centers. Recruitment of consecutive patients should have limited selection bias, however. In addition, our inclusion criteria allowed us to study various conditions and treatments. Second, the physician response rate was low (33.5\%) despite reminders. Third, we studied only 128 patients. Fourth, estimates of drug adherence and importance according to patients and physicians were obtained with different scales: a validated instrument providing an accurate measurement of patient medicine-taking behaviors and a shorter rating scale for physicians to ensure feasibility. To assess drug importance according to physicians, we used the same wording and scale as for the assessment of patient drug adherence to ensure acceptability by physicians. The metric properties of the 2 measurements for physicians have not been evaluated. The differences we observed might thus have been due to the 
questionnaires we chose ${ }_{i}$ however, despite our use of nonvalidated scales, our results are consistent with previous studies documenting that physicians are inaccurate estimators of adherence and have "no better than chance" judgment of which patients are adherent and which are not. ${ }^{19,41}$ Finally, we were not able to study drug appropriateness, for example, by using START (Screening Tool to Alert doctors to Right Treatment) and STOPP (Screening Tool of Older Person's Prescriptions) criteria, ${ }^{27,42}$ because our aim was not to critique drug prescriptions, but rather to compare different subjective opinions and patient behaviors to describe the patient-physician relationship.

\section{Future Research}

More studies are needed to confirm our findings. Future studies could compare measurements from our instrument against other measurements such as those from electronic monitoring devices. Moreover, our results highlight the complexity of medication nonadherence and the importance of dialogue between physicians and patients. The first step in solving nonadherence to medication could be to develop interventions to improve the prescribing process by using shared decision-making techniques so that prescribers consider patient expectations and beliefs when prescribing drugs. Future research could also study the impact of deprescription of drugs considered secondary by physicians and actually not taken by patients, in terms of both economics and avoidable adverse effects.

To read or post commentaries in response to this article, see it online at http://www.annfammed.org/content/14/5/415.

Key words: medication adherence; drug therapy; physician-patient relation; drug prescription; practice-based research; primary care

Submitted December 22, 2015; submitted, revised, April 14, 2016; accepted April 27, 2016.

Funding support: Our team is supported by an academic grant from the program "Equipe espoir de la Recherche," Fondation pour la Recherche Médicale, Paris, France (grant DEQ20101221475).

Disclaimer: The funders had no role in study design, data collection and analysis, decision to publish, or preparation of the manuscript.

Acknowledgments: We thank Laura Smales for reviewing the manuscript before submission.

Supplementary materials: Available at http://www.AnnFamMed. org/content/14/5/415/suppl/DC1/.

\section{References}

1. Ho PM, Rumsfeld JS, Masoudi FA, et al. Effect of medication nonadherence on hospitalization and mortality among patients with diabetes mellitus. Arch Intern Med. 2006;166(17):1836-1841.

2. Simpson SH, Eurich DT, Majumdar SR, et al. A meta-analysis of the association between adherence to drug therapy and mortality. BMJ. 2006;333(7557):15.
3. Osterberg L, Blaschke T. Adherence to medication. N Engl J Med. 2005;353(5):487-497.

4. Lehane E, McCarthy G. Intentional and unintentional medication non-adherence: a comprehensive framework for clinical research and practice? A discussion paper. Int J Nurs Stud. 2007;44(8):1468-1477.

5. Vrijens B, Vincze G, Kristanto $P$, Urquhart J, Burnier $M$. Adherence to prescribed antihypertensive drug treatments: Iongitudinal study of electronically compiled dosing histories. BMJ. 2008;336(7653): 1114-1117.

6. Donovan JL, Blake DR. Patient non-compliance: deviance or reasoned decision-making? Soc Sci Med. 1992;34(5):507-513.

7. Gadkari AS, McHorney CA. Unintentional non-adherence to chronic prescription medications: how unintentional is it really? BMC Health Serv Res. 2012;12:98.

8. McHorney CA, Gadkari AS. Individual patients hold different beliefs to prescription medications to which they persist vs nonpersist and persist vs nonfulfill. Patient Prefer Adherence. 2010;4:187-195.

9. Lau DT, Briesacher BA, Mercaldo ND, et al. Older patients' perceptions of medication importance and worth: an exploratory pilot study. Drugs Aging. 2008;25(12):1061-1075.

10. Viana M, Laszczynska O, Mendes S, et al. Medication adherence to specific drug classes in chronic heart failure. J Manag Care Spec Pharm. 2014;20(10):1018-1026.

11. Gardner EM, Sharma S, Peng G, et al. Differential adherence to combination antiretroviral therapy is associated with virological failure with resistance. AIDS. 2008;22(1):75-82.

12. Osterberg LG, Urquhart J, Blaschke TF. Understanding forgiveness: minding and mining the gaps between pharmacokinetics and therapeutics. Clin Pharmacol Ther. 2010;88(4):457-459.

13. Chin MH, Drum ML, Jin L, Shook ME, Huang ES, Meltzer DO. Variation in treatment preferences and care goals among older patients with diabetes and their physicians. Med Care. 2008;46(3):275-286.

14. Devereaux PJ, Anderson DR, Gardner MJ, et al. Differences between perspectives of physicians and patients on anticoagulation in patients with atrial fibrillation: observational study. BMJ. 2001; 323(7323):1218-1222.

15. Huber CA, Szucs TD, Rapold R, Reich O. Identifying patients with chronic conditions using pharmacy data in Switzerland: an updated mapping approach to the classification of medications. BMC Public Health. 2013;13(1):1030.

16. Sidorkiewicz S, Tran V, Cousyn C, Perrodeau E, Ravaud E. Development and validation of an instrument to assess treatment adherence for each individual drug taken by a patient. BMJ Open. 2016;6(5): e010510.

17. McHorney CA. The Adherence Estimator: a brief, proximal screener for patient propensity to adhere to prescription medications for chronic disease. Curr Med Res Opin. 2009;25(1):215-238.

18. Lu M, Safren SA, Skolnik PR, et al. Optimal recall period and response task for self-reported HIV medication adherence. AIDS Behav. 2008;12(1):86-94.

19. Zeller A, Taegtmeyer A, Martina B, Battegay E, Tschudi P. Physicians' ability to predict patients' adherence to antihypertensive medication in primary care. Hypertens Res. 2008;31(9):1765-1771.

20. Juniper EF, Guyatt GH, Jaeschke R. How to develop and validate a new quality of life instrument. In: Spilker B, ed, Quality of Life and Pharmacoeconomics in Clinical Trials. 2nd ed. New York, NY: Raven Press Ltd; 1996:49-56.

21. Mukaka MM. Statistics corner: a guide to appropriate use of correlation coefficient in medical research. Malawi Med J. 2012;24(3):69-71.

22. Barber N, Parsons J, Clifford S, Darracott R, Horne R. Patients' problems with new medication for chronic conditions. Qual Saf Health Care. 2004;13(3):172-175.

23. Barat I, Andreasen F, Damsgaard EM. Drug therapy in the elderly: what doctors believe and patients actually do. Br J Clin Pharmacol. 2001;51(6):615-622. 
24. Horne R, Weinman J. Patients' beliefs about prescribed medicines and their role in adherence to treatment in chronic physical illness. J Psychosom Res. 1999;47(6):555-567.

25. Mulley AG, Trimble C, Elwyn G. Stop the silent misdiagnosis: patients' preferences matter. BMJ. 2012;345:e6572.

26. Tran VT, Montori VM, Eton DT, Baruch D, Falissard B, Ravaud P. Development and description of measurement properties of an instrument to assess treatment burden among patients with multiple chronic conditions. BMC Med. 2012;10:68.

27. Wallace E, Salisbury C, Guthrie B, Lewis C, Fahey T, Smith SM. Managing patients with multimorbidity in primary care. BMJ. 2015;350:h176.

28. Muth C, van den Akker M, Blom JW, et al. The Ariadne principles: how to handle multimorbidity in primary care consultations. BMC Med. 2014;12:223.

29. National Collaborating Centre for Primary Care. Medicines Adherence: Involving Patients in Decisions About Prescribed Medicines and Supporting Adherence. London, UK: NICE, 2009.

30. May C, Montori VM, Mair FS. We need minimally disruptive medicine. BMJ. 2009;339:b2803.

31. Starfield B, Wray C, Hess K, Gross R, Birk PS, D'Lugoff BC. The influence of patient-practitioner agreement on outcome of care. Am J Public Health. 1981;71(2):127-131.

32. Christensen AJ, Howren MB, Hillis SL, et al. Patient and physician beliefs about control over health: association of symmetrical beliefs with medication regimen adherence. J Gen Intern Med. 2010;25(5): 397-402.

33. Arbuthnott A, Sharpe D. The effect of physician-patient collaboration on patient adherence in non-psychiatric medicine. Patient Educ Couns. 2009;77(1):60-67.
34. Lehmann A, Aslani P, Ahmed R, et al. Assessing medication adherence: options to consider. Int J Clin Pharm. 2014;36(1):55-69.

35. Koschack J, Marx G, Schnakenberg J, Kochen MM, Himmel W. Comparison of two self-rating instruments for medication adherence assessment in hypertension revealed insufficient psychometric properties. J Clin Epidemiol. 2010;63(3):299-306.

36. Ose D, Mahler C, Vogel I, Ludt S, Szecsenyi J, Freund T. Let's talk about medication: concordance in rating medication adherence among multimorbid patients and their general practitioners. Patient Prefer Adherence. 2012;6:839-845.

37. Smith WE. Role of a pharmacist in improving rational drug therapy as part of the patient care team. Ann Pharmacother. 2007;41(2): 330-335.

38. Mino-León D, Reyes-Morales H, Flores-Hernández S. Effectiveness of involving pharmacists in the process of ambulatory health care to improve drug treatment adherence and disease control. J Eval Clin Pract. 2015;21(1):7-12.

39. Safran DG. Defining the future of primary care: what can we learn from patients? Ann Intern Med. 2003;138(3):248-255.

40. Reeve $E$, Wiese MD. Benefits of deprescribing on patients' adherence to medications. Int J Clin Pharm. 2014;36(1):26-29.

41. Phillips LA, Leventhal EA, Leventhal $H$. Factors associated with the accuracy of physicians' predictions of patient adherence. Patient Educ Couns. 2011;85(3):461-467.

42. Gallagher P, Ryan C, Byrne S, Kennedy J, O'Mahony D. STOPP (Screening Tool of Older Person's Prescriptions) and START (Screening Tool to Alert doctors to Right Treatment). Consensus validation. Int J Clin Pharmacol Ther. 2008:46(2):72-83. 